\title{
SEGUIMIENTO DEL PRECEDENTE POR LA CORTE SUPREMA DE CHILE EN MATERIA LABORAL. ESTUDIO EMPÍRICO DEL RECURSO DE UNIFICACIÓN DE JURISPRUDENCIA*
}

\author{
FOLLOWING OF THE CHILEAN SUPREME SORT PRECEDENT IN \\ LABOR MATTERS. EMPIRICAL STUDY OF THE JURISPRUDENCE \\ UNIFICATION RECOURSE
}

\author{
L. IVÁn Díaz García \\ Sofía Alarcón García \\ Katerine Cempe Cempe \\ Luis Alejandro Garrido Esparza \\ Alejandro ZúNiga Garrido ${ }^{* *}$
}

\begin{abstract}
RESUMEN: El presente trabajo analiza el seguimiento de sus propios precedentes por parte de la Corte Suprema de Chile en materia laboral. Para estos efectos se analizan las decisiones adoptadas en los 1.051 recursos de unificación de jurisprudencia deducidos en el cuadrienio que se inicia con la incorporación de este recurso al ordenamiento jurídico nacional. Este estudio empírico permite concluir que la sala laboral de la Corte Suprema sigue sus propios precedentes en el $100 \%$ de los casos en que el recurso se declara admisible.
\end{abstract}

Palabras clave: Unificación de jurisprudencia, Precedente, Jurisprudencia, Corte Suprema, Derecho del trabajo.

ABSTRACT: This research analyzes how the Chilean Supreme Court follows its own precedents in labor matters. Therefore, the decisions made on the 1051 unification of jurisprudence recourse deduced in the four year period that began with the incorporation of this recourse to the national legal system are analyzed. This empirical study allows us to conclude that the Supreme Court labor chamber does follow its own precedents in a $100 \%$ of the cases on which the recourse is declared admissible.

Key words: Unification of jurisprudence, Precedent, Case law, Supreme Court, Labor Law.

\footnotetext{
Esta investigación ha sido desarrollada en el marco de la ejecución del proyecto FONDECYT 11121310, cuyo investigador responsable es Luis Iván Díaz García.

Los autores agradecen los amables comentarios a una versión preliminar de este trabajo efectuados por los siguientes académicos de la Facultad de Ciencias Jurídicas de la Universidad Católica de Temuco: Alberto Olivares, Mónica Baeza, Alejandra Cid, Scarlette Lagos, Juan Pablo Beca, Eduardo Castillo, Juan Eduardo Fernández, Juan Jorge Faundes y Darío Parra. Los errores que subsisten son, evidentemente, de exclusiva responsabilidad de los autores.

** L. Iván Díaz García es académico en la Facultad de Ciencias Jurídicas de la Universidad Católica de Temuco (Chile) e integrante del Grupo de Investigaciones Jurídicas de la misma. Abogado Pontificia Universidad Católica de Chile. Doctor en Derecho Universidad Carlos III de Madrid, España. Correo electrónico: ivandiaz@ uct.cl. Sofía Alarcón García es egresada de Derecho por la Universidad Católica de Temuco. Correo electrónico: palarcon2009@alu.uct.cl. Katerine Cempe Cempe es egresada de Derecho por la Universidad Católica de Temuco. Correo electrónico: kcempre2009@alu.uct.cl. Luis Alejandro Garrido Esparza es egresado de Derecho por la Universidad Católica de Temuco. Correo electrónico: lgarridoe2009@alu.uct.cl. Alejandro Zúñiga Garrido egresado de Derecho por la Universidad Católica de Temuco. Correo electrónico: azunigag2009@alu.uct.cl.
} 


\section{INTRODUCCIÓN}

Una negativa evaluación del sistema recursivo y de otros aspectos procesales introducidos al Código del Trabajo por la ley 20.087 condujo a la presentación de un proyecto de ley que dio lugar a la ley 20.260, que se publicó en el Diario Oficial el 29 de marzo de 2008. Junto con regular otros aspectos procedimentales, esta iniciativa incorporó al ordenamiento jurídico chileno el recurso de unificación de jurisprudencia laboral, el que debía ser conocido por la Corte Suprema. Su finalidad fue, según aparece de diversos antecedentes, uniformar la jurisprudencia en el ámbito del Derecho del trabajo.

En ese contexto, el presente trabajo tiene por finalidad determinar si se ha producido, en los hechos, un seguimiento interno e institucional de los precedentes establecidos por la Corte Suprema al resolver los recursos de unificación de jurisprudencia que han sido sometidos a su decisión. Al respecto se debe tener presente que el seguimiento interno es el que se produce por parte de un determinado órgano jurisdiccional, la Corte Suprema en este caso, respecto de sus propias decisiones anteriores. Con la expresión "seguimiento institucional", por su parte, se alude a que es el tribunal como órgano jurisdiccional el que se somete a los precedentes, sin considerar las opciones adoptadas por cada uno de sus ministros en particular.

Para cumplir dicha finalidad, la presente investigación revisa los recursos de unificación de jurisprudencia deducidos en el cuadrienio que sigue a la fecha en que inició su vigencia este medio de impugnación, es decir, desde el 30 de marzo de 2008 y hasta el 29 de marzo de 2012. Esto implica analizar sentencias pronunciadas entre el 19 de noviembre de 2008 y el 11 de abril de 2013 pues, como puede suponerse, la resolución de dichos recursos tardó algún tiempo en ser emitida por la Corte Suprema.

Desde el punto de vista de su estructura, el trabajo se divide en tres partes. La primera de ellas constituye el marco teórico en el que se precisa la finalidad del recurso de unificación de jurisprudencia y a qué se alude cuando se habla de seguimiento del precedente. La segunda parte expresa la metodología aplicada y detalla cada uno de los pasos seguidos para arribar a los resultados alcanzados. La tercera parte expone tales resultados distinguiendo ciertos aspectos preliminares del análisis de los recursos útiles para la investigación. El estudio concluye con las correspondientes conclusiones.

\section{MARCO TEÓRICO}

\section{Sobre la finAlidad del ReCURSo de UnificaCión de JURISPRUdENCIA}

El recurso de unificación de jurisprudencia constituye, sin duda, una importante innovación en el ordenamiento jurídico chileno. Esto se debe a que por primera vez se establece un medio de impugnación de resoluciones judiciales cuya finalidad es asegurar el seguimiento de los precedentes establecidos por la Corte Suprema, en este caso en el ámbito laboral. Aunque esta afirmación constituye un supuesto de trabajo de la presente investigación, a continuación se ofrecen concisamente algunos antecedentes que permiten justificarlo ${ }^{1}$.

\footnotetext{
1 Resulta pertinente reconocer que existen argumentos que contradicen este supuesto. No obstante, su presentación y refutación exceden los fines del presente trabajo, de modo que han de ser objeto de otra investigación.
} 


\subsection{Antecedentes ofrecidos durante la tramitación parlamentaria de la ley}

Un primer antecedente sobre la finalidad del recurso de unificación de jurisprudencia se encuentra en las explicaciones ofrecidas durante la tramitación parlamentaria del proyecto que dio lugar a la ley 20.260, en que se gestó este medio de impugnación. En la oportunidad se expresó que los asesores legislativos de los diversos sectores estaban redactando una propuesta de consenso, que incluía el nuevo recurso de unificación de jurisprudencia. La finalidad de este último era "obtener una interpretación uniforme por parte de la Corte Suprema para que, en definitiva, fije el sentido de las normas laborales, ya que la circunstancia habilitante para acceder a esa sede superior es precisamente la existencia de pronunciamientos contradictorios en la jurisprudencia"'.

Una vez presentada la referida propuesta, se ofrecieron nuevas razones que permiten concluir que la finalidad del nuevo recurso era incorporar algún grado de seguimiento del precedente. En este sentido, los asesores del Ejecutivo sostuvieron que "estas normas consagran un recurso de derecho estricto, cuya finalidad no es sanear un vicio como acontece con el recurso de nulidad, sino que su objetivo es unificar la jurisprudencia emanada de los tribunales superiores de justicia. De ahí que, para interponerlo, es necesario invocar la existencia de otros fallos, sea que provengan de las Cortes de Apelaciones o de la propia Corte Suprema, referidos a los mismos puntos de derecho, pero cuyas fundamentaciones jurídicas son contradictorias con las de la sentencia que se pretende impugnar". En este sentido, se explicó que la finalidad era establecer un precedente respecto del modo en que se debía interpretar una determinada materia de Derecho ${ }^{3}$. En el mismo sentido se pronunció uno de los asesores de la oposición, quien sostuvo que este recurso "es muy similar a otros consagrados en el derecho comparado, como la casación francesa o el recurso que se interpone ante la Suprema Corte de Estados Unidos de América para uniformar los fallos de tribunales estatales"4.

\subsection{Antecedentes relativos a la pretensión de uniformar la jurisprudencia}

No solo los antecedentes relacionados con la historia de la ley 20.260 conducen a sostener que el objetivo del recurso en análisis ha sido introducir el seguimiento del precedente. A la misma conclusión, aunque de manera inferencial, conducen la denominación de este medio de impugnación, su regulación y la opinión de la doctrina respecto de su finalidad.

En cuanto a su denominación, el que se le haya llamado de unificación de jurisprudencia evidencia que con él se ha pretendido uniformar la doctrina judicial en el ámbito laboral, esto es, estandarizar la interpretación que la Corte Suprema hace de las normas que aplica a los casos regidos por el Derecho del trabajo.

En lo relativo a su regulación, el recurso procede "cuando respecto de la materia de derecho objeto del juicio existieren distintas interpretaciones sostenidas en uno o más fallos

\footnotetext{
2 Biblioteca del Congreso Nacional, Historia de la ley 20.260, p. 218.

3 Biblioteca del Congreso Nacional, Historia de la ley 20.260, p. 283.

4 Estas explicaciones fueron vertidas por Rodrigo Delaveau, abogado vinculado a Libertad y Desarrollo, uno de los centros de estudios asesores de la en ese momento oposición de Derecha. Ver Biblioteca Del Congreso NaCional, Historia de la ley 20.260, p. 272.
} 
firmes emanados de Tribunales Superiores de Justicia” (artículo 483, inciso segundo, del Código del Trabajo). Por lo mismo el recurso debe ser declarado inadmisible si el escrito que lo contiene carece de "una relación precisa y circunstanciada de las distintas interpretaciones respecto de las materias de derecho objeto de la sentencia, sostenidas en diversos fallos emanados de los Tribunales Superiores de Justicia” o no acompaña las respectivas sentencias (artículo 483-A, inciso segundo, del Código del Trabajo). Esta regulación del instituto procesal en cuestión permite concluir que es condición de su admisibilidad y procedencia la existencia de dispersión jurisprudencial, por lo que resulta evidente que con él se pretende uniformar la jurisprudencia hacia el futuro.

En cuanto a la opinión de los autores respecto de la finalidad del recurso de unificación de jurisprudencia laboral, existe consenso en admitir que con él se pretende uniformar la doctrina judicial. Aunque las fórmulas semánticas elegidas son diversas, tales como que con dicho recurso se persigue "establecer unificado algún criterio jurisprudencial", "unificar las interpretaciones judiciales existentes" u "obtener una interpretación uniforme", con todas ellas se alude al mismo objetivo. En este sentido se pronuncian, por ejemplo, Hugo Fábrega ${ }^{5}$, Fernando Halim ${ }^{6}$, Halpern y Humeres ${ }^{7}$, Gabriela Lanata ${ }^{8}$ y Camila Odette ${ }^{9}$.

En suma, la denominación del recurso, su regulación y la opinión de los autores respecto de su finalidad permiten concluir que su objetivo es la uniformidad jurisprudencial. Pues bien, con acierto expresan Couso y Mera que dicha uniformidad depende del grado de seguimiento que tengan los precedentes de la Corte Suprema ${ }^{10}$. Esto se debe a que si en cada caso se sigue la interpretación previamente sostenida por el Máximo Tribunal, entonces se genera una jurisprudencia unívoca. Si, por el contrario, la disposición es interpretada cada vez de una manera diversa al caso anterior, no se produce aquella uniformidad. De este modo, si se afirma que la finalidad del recurso en análisis es uniformar la jurisprudencia, lo que se está sosteniendo, de manera lógicamente necesaria, es que con él se pretende que exista algún grado de seguimiento de los precedentes, esto es, de las ratio decidendi establecidas en sentencias anteriores al caso que debe ser decidido en el presente.

\section{Sobre El SIGNifiCAdo DE "SEgUimiento DEL PRECEDENTE"}

En general, se denomina precedente a un evento que ha ocurrido en el pasado y que puede servir de guía para una acción a realizar en el presente ${ }^{11}$. En el ámbito procesal, la expresión precedente tiene un significado más preciso: es la razón normativa que ha servido de fundamento a lo decidido en un caso anterior que puede servir de guía para decidir un

\footnotetext{
FÁBrega (2010) pp. 530 y 531.

6 Halim (2011) p. 90.

Halpern y Humeres (2010) pp. 346, 350 y 367.

LANATA (2011) pp. 259 y 262.

Odette (2013) p. 444.

10 Couso y Mera (2011) p. 103.

11 En este sentido, expresa Duxbury: "The precedent is a past event -in law the event is nearly always a decisionwhich serves as a guide for present action. Not all past event are precedents. Much of what we did in the past quickly fades in the insignificance (or is best forgotten) and does not guide future actions at all". Ver DuXBURY (2008) p. 1.
} 
caso presente. En la cultura jurídica anglosajona esta razón normativa de lo decidido se denomina ratio decidendi ${ }^{12}$.

La ratio decidendi puede adoptar diversas formas. En efecto, puede tratarse de una definición, de una regla precisa o de un principio jurídico más o menos general ${ }^{13}$. En cualquier caso, y sea cual fuere la forma que adopte, no necesariamente se expresa explícitamente en la sentencia. En efecto, la razón normativa de lo decidido muchas veces puede encontrarse de manera más o menos implícita en el desarrollo argumentativo de la misma ${ }^{14}$.

Ahora bien, una cosa es un precedente y otra bien distinta es el hecho de seguir un precedente. Al respecto conviene tener presente que un estudio coordinado por MacCormick y Summers, publicado en 1997, evidenció que existen diversos grados de vinculación con el precedente ${ }^{15}$. Como conclusión de este estudio, Aleksander Peczenik distingue cuatro gradas o niveles de vinculación ${ }^{16}$ :

a) Vinculación formal: es el grado más intenso de seguimiento de la ratio decidendi contenida en decisiones judiciales anteriores, pues según explica Peczenik, la sentencia que se aparta de aquellas es ilegal y, por tanto, queda sujeta a ser revocada mediante un recurso.

b) Vinculación prima facie: el precedente opera como una regla de decisión que debe ser seguida, a menos que existan buenas razones para apartarse de él. En este sentido, expresa Peczenik que la decisión que no sigue el precedente es legal, pero puede ser criticada en sus fundamentos y objeto de revocación mediante recurso.

c) Vinculación como apoyo adicional: lo previamente decidido constituye un argumento que otorga a la sentencia dictada en el caso actual mayor solidez que si se presenta sin él. Al respecto, Peczenik explica que una decisión que carece de sustento en el precedente es legal y puede estar incluso justificada, pero no tan bien como lo habría estado si hubiere invocado el precedente.

d) Vinculación referencial: la ratio decidendi de un caso anterior tiene mero valor ilustrativo, de modo que la vinculación al precedente es extremadamente débil.

Solo en los dos primeros casos, esto es, en la vinculación formal y en la vinculación prima facie, se puede hablar de seguimiento del precedente. Esto se debe a que solo en ellos el apartamiento de la ratio decidendi estatuida en una sentencia anterior permite revocar lo decidido, precisamente debido a dicho apartamiento. En los dos niveles inferiores, es decir, en la vinculación como apoyo adicional y en la vinculación referencial, no existe seguimiento del precedente. Esto se debe a que una sentencia que diverge de la ratio decidendi establecida en un caso anterior no puede ser revocada debido a esta divergencia, aun cuando pueda serlo por otras razones.

12 Llewellyng (1989) p. 15.

13 WhitTaker (2008) pp. 49 y 50.

14 En este mismo sentido, Siltala (2000) p. 86.

15 MacCormick y Summers (1997).

16 PeCZenik (1997) p. 463. 
Conviene destacar que el precedente, esto es, la ratio decidendi contenida en una sentencia dictada en un caso del pasado, solo resulta aplicable a un caso presente en cuanto existe igualdad entre los hechos de ambos ${ }^{17}$. Esta igualdad no significa, como erróneamente podría suponerse, que debe existir identidad entre tales hechos. Lo que debe existir es coincidencia en todas las propiedades relevantes de los mismos ${ }^{18}$, pues precisamente en ello consiste la igualdad ${ }^{19}$. En consecuencia, el seguimiento del precedente en los casos de vinculación formal y prima facie solo procede cuando existe la igualdad fáctica señalada.

\section{METODOLOGÍA DE TRABAJO}

La metodología de trabajo que se siguió para cumplir el objetivo a que se refiere la presente investigación fue la siguiente: se identificaron los recursos de unificación de jurisprudencia ingresados a la Corte Suprema entre el 30 de marzo de 2008 y el 29 de marzo de 2012; se obtuvieron las respectivas sentencias; a partir de lo resuelto de dichas sentencias, se seleccionaron aquellos recursos que eran útiles para la investigación; los recursos útiles se clasificaron atendiendo a la materia de Derecho objeto del juicio de que trataban; y, por último, se evaluó lo resuelto. A continuación se explican los aspectos relevantes de cada uno de estos pasos metodológicos.

\section{IDENTIFICACIÓN DE LAS CAUSAS}

Según se indicó, el primer paso metodológico consistió en identificar los recursos de unificación de jurisprudencia laboral ingresados a la Corte Suprema entre el 30 de marzo de 2008 y el 29 de marzo de 2012.

Con la finalidad de cruzar los resultados obtenidos y evitar un error en la determinación del universo de sentencias a considerar, esta identificación se realizó por dos vías. Por una parte, se ha revisado el ingreso diario de causas a la Corte Suprema entre el 30 de marzo de 2008 y el 29 de marzo de 2012, de acuerdo con la información ofrecida en la página web del Poder Judicial, tomándose nota de los recursos de unificación de jurisprudencia deducidos en dicho período. Por otra parte, se ha solicitado a la Unidad de Computación y Estadísticas de la Corte Suprema el listado de los recursos de unificación deducidos en el mismo período ${ }^{20}$.

\footnotetext{
$17 \mathrm{Al}$ respecto Cross expresa que es un principio básico de la administración de justicia que los casos iguales deben ser resueltos de la misma manera. Según precisa, esto es suficiente para explicar el hecho que, en casi todas las jurisdicciones, un juez tiende a decidir un caso en el mismo sentido que aquel en el cual un caso similar ha sido decidido por otro juez. Ver Cross (1977) p. 4.

18 En el mismo sentido, Mendonca y Guibourg expresan que "Es obvio que no todas las propiedades son relevantes para la caracterización de un caso. La selección de las propiedades relevantes es, en buena medida, un problema valorativo". Ver Mendonca y Guibourg (2004) p. 187).

19 El significado con que se han utilizado las expresiones igualdad e identidad en el presente trabajo han sido tomadas de Comanducci (1999) p. 84.

20 Conviene hacer presente que no fue posible contrastar las dos vías señaladas con un registro físico de los recursos de unificación ingresados en el período en estudio (como un libro de ingreso de causas). Esto se debe a que la Corte Suprema ya no utiliza estos soportes para dejar constancia de los ingresos. Todo se registra directamente en el sistema informático del Poder Judicial.
} 


\section{OBTENCIÓN DE LAS SENTENCIAS}

La metodología aplicada incluyó como segundo paso la obtención del total de las sentencias recaídas en los 1.052 recursos de unificación de jurisprudencia laboral ingresados a la Corte Suprema en el cuadrienio en estudio. Para este efecto se procedió a la transcripción de las mismas, desde la página web del Poder Judicial hacia documentos en formato word. De este modo se ha formado una base de información con la totalidad de las sentencias dictadas en la materia, la que se encuentra permanentemente a disposición del equipo que realizó esta investigación.

\section{Selección de ReCURSOS Útiles}

El tercer paso consistió en seleccionar los recursos de unificación de jurisprudencia útiles para la investigación. Para este efecto fue necesario clasificarlos atendiendo a la clase de decisión que recayó en cada uno de ellos. Como resultado de dicha clasificación fue posible generar los siguientes universos de recursos: desiertos, no presentados, inadmisibles, desistidos y sentenciados en cuanto al fondo. A continuación se explica el significado de cada una de estas categorías.

a) Desierto. Se declara la deserción del recurso si el recurrente no se hace parte ante la Corte Suprema dentro del plazo de cinco días contados desde que se reciban los autos en la Secretaría de dicha Corte (artículos 200 y 201 del Código de Procedimiento Civil, aplicable supletoriamente por disposición del artículo 432 del Código del Trabajo).

b) No presentado. El recurso se tiene por no presentado si no se acompañan tantas copias cuantas sean las partes a las que deba notificarse la providencia que en él recaiga o si existe disconformidad sustancial entre el original y las copias, y la parte no cumple el apercibimiento del tribunal, en orden a acompañar las copias dentro de tercero día (artículo 31 del Código de Procedimiento Civil, aplicable supletoriamente por disposición del artículo 432 del Código del Trabajo).

c) Inadmisible. La sala especializada de la Corte Suprema debe declarar la inadmisibilidad del recurso si no se presenta ante la Corte de Apelaciones respectiva, se interpone fuera del plazo fatal de quince días establecido al efecto, carece de fundamentos, no contiene una relación precisa de las distintas interpretaciones respecto de la materia de Derecho objeto del juicio sostenidas en diversos fallos emanados de los tribunales superiores o no se acompañan las sentencias que se invocan como fundamento (artículo 483-A, inciso séptimo, del Código del Trabajo) ${ }^{21}$.

21 La Corte de Apelaciones también debe declarar la inadmisibilidad del recurso si se presenta fuera del plazo de 15 días contados desde la notificación de la sentencia que se recurre (artículo 483-A, inciso tercero, del Código del Trabajo, en relación con el inciso primero del mismo artículo). Sin embargo, esta posibilidad resulta irrelevante para la presente investigación por cuanto solo se consideran los recursos de unificación de jurisprudencia ingresados a la Corte Suprema, lo que no ocurre con los que la respectiva Corte de Apelaciones declara inadmisibles. 
d) Desistido. El recurso se tiene por desistido si la parte retira el recurso, lo que extingue la acción deducida (artículos 148 y 150 del Código de Procedimiento Civil, aplicable supletoriamente por disposición del artículo 432 del Código del Trabajo) ${ }^{22}$.

e) Sentenciado. Se trata de aquellos recursos de unificación respecto de los cuales la Corte Suprema ha emitido pronunciamiento en el sentido de acoger o rechazar el recurso deducido, una vez superadas las posibles salidas procesales señaladas en las precedentes letras a) a d).

\section{Clasificación de los recursos sentenciados}

La metodología aplicada incluyó como cuarto paso clasificar los recursos sentenciados, de acuerdo con la materia de Derecho objeto del juicio a que se referían los mismos. Para estos efectos se entiende por materia de Derecho objeto del juicio, que es la expresión utilizada por el artículo 483 del Código del Trabajo, el problema de relevancia jurídica que ha sido sometido a la decisión de la Corte Suprema.

Esta clasificación permitió agrupar los recursos útiles en diversos universos. Cada uno de estos universos estaba compuesto por uno o más recursos en los que existía pronunciamiento sobre una determinada materia de Derecho objeto del juicio, diversa por cierto de la que correspondía a otro de estos mismos universos.

Ahora bien, como el objetivo de la presente investigación consiste en evaluar si existe seguimiento del precedente interno, resultó posible distinguir entre universos útiles y universos inútiles. Los universos útiles son aquellos en que una misma materia de derecho es resuelta en dos o más causas, pues solo de este modo resulta posible evaluar si se respeta la ratio decidendi establecida anteriormente. Los universos inútiles son, evidentemente, aquellos constituidos por un solo recurso, pues en tales casos no existe otra resolución con la cual comparar y, por tanto, evaluar si existe seguimiento del precedente.

\section{EVALUACIÓN DE LOS UNIVERSOS ÚTILES}

La metodología aplicada incluyó, como último paso, la evaluación de lo resuelto en cada uno de los universos útiles. En otras palabras, se analizó cada uno de los universos constituidos por dos o más recursos que trataban una misma materia de Derecho objeto del juicio en los que existía pronunciamiento sobre el fondo.

Esta evaluación implicó dos cosas. En primer lugar, identificar la ratio decidendi aplicada en cada una de las sentencias dictadas en los recursos que conformaban un determinado universo útil. En segundo lugar, analizar si la Corte Suprema aplicó la misma ratio decidendi a la materia de Derecho objeto del juicio que era sometida a su decisión en todos los recursos que conformaban dicho universo. De este modo, resultó posible arribar a la conclusión pretendida por esta investigación, cual es si la Corte Suprema, como órgano ju-

\footnotetext{
22 También se tiene por desistido al recurrente si no deposita en la Secretaría del Tribunal la cantidad de dinero necesaria para las fotocopias el expediente que deben ser enviadas a la Corte Suprema (artículo 197 del Código de Procedimiento Civil, aplicable supletoriamente por disposición del artículo 432 del Código del Trabajo). Sin embargo, esta posibilidad resulta irrelevante a efectos de la presente investigación, debido a que dicha declaración de desistimiento corresponde a la Corte de Apelaciones y no a la Corte Suprema.
} 
risdiccional, ha seguido sus propios precedentes contenidos en las sentencias de unificación de jurisprudencia laboral.

\section{RESULTADOS}

\section{IDENTIFICACIÓN DE LOS UNIVERSOS ÚTILES}

En el proceso de identificación de los recursos de unificación de jurisprudencia ingresados a la Corte Suprema entre el 30 de marzo de 2008 y el 29 de marzo de 2012 se evidenció una discrepancia entre la información proveída por la Unidad de Computación y Estadísticas de la Corte Suprema y la información disponible en la página web del Poder Judicial. La primera registra un total de 1.047 recursos de unificación de jurisprudencia ingresados en el cuadrienio en estudio. La segunda, en cambio, da cuenta de 1.052, esto es, cinco ingresos más que la referida Unidad en el mismo período ${ }^{23}$. Como estos cinco ingresos son efectivamente recursos de unificación de jurisprudencia, han sido incluidos para efectos del presente estudio. De este modo, entre el 30 de marzo de 2008 y el 29 de marzo de 2012 ingresaron 1.052 recursos de unificación de jurisprudencia laboral a la Corte Suprema. Como uno de estos 1.052 ingresos se acumuló a otro ${ }^{24}$, de modo que sobre ambos recursos de unificación recayó una misma decisión final, son 1.051 el total de recursos que será objeto del presente estudio.

Ahora bien, de los 1.051 recursos recién mencionados, solo 227 se incluyen en la categoría "sentenciados", esto es, entre aquellos respecto de los cuales la Corte Suprema se pronunció acogiendo o rechazando el recurso de unificación de jurisprudencia deducido. Los otros 824 fueron objeto de alguna de las siguientes clases de decisión: desiertos, no presentados, inadmisibles o desistidos. El siguiente cuadro muestra la situación de cada uno de los 1.051 recursos de acuerdo con las decisiones recaídas en los mismos:

\begin{tabular}{|c|c|c|c|c|c|}
\hline Desierto & No presentado & Inadmisible & Desistido & Sentenciado & Total \\
\hline 166 & 44 & 596 & 18 & 227 & 1.051 \\
\hline
\end{tabular}

Al revisar los 227 recursos incluidos en la categoría "sentenciados" con la finalidad de separarlos atendiendo a la materia de Derecho objeto del juicio, fue posible advertir que en algunos casos la Corte Suprema no se pronunció respecto de dicha materia. En lugar de ello, los resolvió aplicando lo que de un modo genérico se pueden llamar causales de inadmisibilidad, aunque tardíamente declaradas ${ }^{25}$. En esta situación se encuentran 61 de

\footnotetext{
23 Los cinco recursos de unificación de jurisprudencia que constan en la página web del Poder Judicial y que no se registran en la información proveída por la Unidad de Computación y Estadísticas de la Corte Suprema son los siguientes: rol 5164-2008, con sentencia del 28 de octubre del 2008; rol 7355-2008, con sentencia del 11 de marzo de 2009; rol 1651-2009, con sentencia del 2 de abril de 2009; rol 3158-2009, con sentencia del 18 de junio de 2009; y rol 9301-2009, con sentencia del 31 de marzo de 2010.

24 Se trata del recurso rol 6415-2010, que se acumuló al recurso rol 4371-2010.

25 En estos casos los recursos de unificación fueron desestimados, por ejemplo, porque los hechos que fundan el recurso son distintos respecto de aquellos contenidos en las sentencias acompañadas; en las sentencias acompañadas existe el mismo lineamiento jurisprudencial contenido en el recurso de nulidad impugnado; el recurso de nulidad no se pronuncia sobre el debate de fondo; existe contradicción entre los fundamentos de derecho
} 
las 227 causas, las que carecen de interés para el presente estudio precisamente porque en ellas no existe un pronunciamiento respecto de la materia de Derecho objeto del juicio. Conviene reconocer que este subgrupo no estaba previsto en la metodología expuesta en el apartado anterior.

De este modo, es decir, descontados los 61 recursos rechazados por causales de inadmisibilidad tardíamente declaradas, son 166 los recursos de unificación de jurisprudencia que en definitiva fueron agrupados atendiendo a la materia de Derecho objeto del juicio. La referida agrupación generó 45 universos. De esos universos, 28 estaban constituidos por una sola causa, de modo que, por resultar imposible evaluar si en tales casos había seguimiento del precedente, no eran útiles para la investigación. Esto condujo a la exclusión de los 28 recursos que respectivamente conformaban estos universos inútiles.

La exclusión de estos 28 universos, y sus respectivos 28 recursos de unificación de jurisprudencia, reduce la investigación a 17 universos (por cierto cada uno integrado por dos o más causas) que en conjunto reúnen 141 recursos. A ellos se restringe el análisis que sigue, pues solo en ellos es posible evaluar si se ha producido el seguimiento interno del precedente por la Corte Suprema como órgano jurisdiccional.

\section{Materias de DERECHO ObJeTO Del JUiCiO EN LOS UNIVERSOS ÚtILES}

Las materias de Derecho objeto del juicio en los 17 universos útiles identificados, y en los cuales se distribuyen los referidos 141 recursos de unificación de jurisprudencia laboral, son las siguientes ${ }^{26}$ :

1) Aplicación de las normas sobre indemnización por años de servicios e indemnización sustitutiva del aviso previo reguladas en el Código del Trabajo a profesionales de la educación contratados anualmente por varios períodos consecutivos.

La Corte Suprema se ha pronunciado en dos oportunidades respecto de esta materia de Derecho ${ }^{27}$. En ambas ha establecido como regla de decisión que no resulta procedente la aplicación supletoria de los artículos 7, 162 y 163 del Código del Trabajo a profesionales de la educación municipal, contratados anualmente sin solución de continuidad por varios períodos continuos. Esta interpretación se funda en que el Estatuto Docente (Ley 19.070) establece su propia regulación respecto de la materia tratada en dichos artículos y, por ende, no resulta procedente la aplicación supletoria referida en el artículo 71 de este último cuerpo legal.

En consecuencia, la Corte Suprema ha establecido una determinada interpretación frente a esta materia de Derecho y la ha seguido.

en los que se sustenta el recurso de unificación, en relación al pronunciamiento que en definitiva se solicita a la Corte Suprema; y las sentencias que se acompañan para fundar el recurso no se pronuncian sobre la materia de derecho que se pretende unificar.

26 Se debe tener presente que la sentencia dictada por la Corte Suprema en el recurso de unificación de jurisprudencia rol 7871/2011 trata dos materias de Derecho. Por ello el total de recursos citados en las notas al pie se eleva a 142 .

27 Las dos causas son las siguientes: Orellana con Ilustre Municipalidad de El Monte (2010), Tudela con Corporación Municipal de Servicio y Desarrollo de Maipú (2011). 
2) Procedencia de la sanción establecida en el artículo 162, inciso séptimo, cuando la existencia de la relación laboral ha sido establecida por sentencia judicial.

La Corte Suprema se ha pronunciado en nueve oportunidades respecto de esta materia de Derecho ${ }^{28}$. Al respecto ha establecido como ratio decidendi que no procede la aplicación de la sanción del artículo 162, inciso séptimo, cuando la existencia de la relación laboral ha sido establecida por sentencia judicial. El fundamento de dicha regla es que para el empleador la relación laboral solo surgió desde la dictación de la sentencia.

En consecuencia, la Corte Suprema ha establecido y seguido su propio precedente, es decir, la interpretación que previamente ha sostenido, en esta materia de Derecho.

3) Procedencia de la sanción establecida en el artículo 162, inciso séptimo, cuando la diferencia entre la remuneración pagada y la devengada favorece al trabajador y esto ha sido establecido por sentencia judicial.

La Corte Suprema se ha pronunciado en seis oportunidades respecto de esta materia de Derecho ${ }^{29}$. Al respecto ha sostenido como razón para la decisión de esos seis casos que la sanción prevista en el inciso séptimo del artículo 162 del Código del Trabajo, no se aplica al empleador cuando ha sido la sentencia la que ha determinado que la remuneración del trabajador era superior a la estipulada en el contrato y respecto de esta diferencia estableci$\mathrm{da}$ en su favor, no se han retenido ni enterado cotizaciones previsionales.

En consecuencia, la Corte Suprema ha establecido una ratio decidendi y la ha seguido en todos los casos en que se ha debido pronunciar sobre esta materia de Derecho.

4) Procedencia del beneficio establecido en el inciso primero del artículo 45 (semana corrida) a los trabajadores con remuneración mixta cuya parte variable no se devenga día a día.

La Corte Suprema se ha pronunciado en veinte oportunidades respecto de esta materia de Derecho ${ }^{30}$. Sobre el punto en todos ellos estableció como regla que los trabajadores incorporados en la parte final del inciso primero del artículo 45 del Código del Trabajo,

28 Las nueve causas son las siguientes: Núnez con Sociedad Contractual Minera Tambillos (2010); Villanueva con Fisco de Chile Armada de Chile (2010); Araya con Bodega La Esperanza Viñedos Errázuriz Ovalle S.A. (2010); Soza con Televisión Nacional de Chile (2011); Acosta y Otros con Sociedad Depetris Deflorian Hnos. Ltda. (2011); Araya con Monte Nevado Ingeniería y Otros (2010); Orrego con Empresa Periodística La Cuarta S.A. (2011); Olivares con Pontificia Universidad Católica de Chile (2012); y Riquelme con Pontificia Universidad Católica de Chile Corporación de Televisión (2012).

29 Las seis causas son las siguientes: Saldaña con Interagro Comercio y Ganado S.A. (2009); Pereira con Consorcio RDTC S.A. (2010); Abello con Librería Giorgio Temuco y CIA Limitada (2011); Boasso con Rosa (2011); Dussuel con Colegio San Bartolomé De Nos S.A. (2011); y Véliz con TP Chile S.A. (2012).

30 Las veinte causas son las siguientes: A.F.P. Provida con Román (2010); Gómez con ING AFP Capital S.A. (2010); Prado con ING AFP Capital S.A. (2010); Reyes con A.F.P. Próvida S.A. (2010); Cabrera con A.F.P. Próvida S.A. (2010); Pereira con A.F.P. Próvida S.A. (2010); Cáceres con ING AFP Capital S.A. (2010); Monroy y otra con AFP Hábitat S.A. (2010); Rencoret y Otro con AFP Provida S.A. (2010); Caro y Otros con AFP Provida S.A. (2010); Sindicato de Trabajadores de la AFP Provida S.A. con AFP Provida S.A. (2011); Valenzuela con AFP Capital S.A. (2010); Osses y Otros con AFP Habitat S.A. (2011); Alarcón con Administradora de Fondos de Pensiones Capital S.A. (2011); Sindicato Unificado de Trabajadores de Isapre Banmédica S.A. con Isapre Banmédica S.A. (2011); Aravena y Otros con VTR Global Com S.A. (2011); Gonzáles y Otros con AFP Provida S.A. (2011); Parada con AFP Capital S.A. (2011); Corte Suprema, Kerbernhard con Recaudación y Cobranzas S.A. (2011); y Irazzoky con Comercial Rey S.A. (2011). 
afectos a un sistema remuneracional mixto, integrado por sueldo mensual y remuneraciones variables, solo tienen derecho al pago de la semana corrida en la medida que sus remuneraciones variables sean devengadas día a día.

En consecuencia, la Corte Suprema ha establecido una razón para la decisión en esta materia de Derecho y la ha seguido en todos los casos referidos a la misma.

5) Inclusión de asignaciones que no constituyen remuneración en el concepto última remuneración mensual del artículo 172 del Código del Trabajo.

La Corte Suprema se ha pronunciado en dieciséis oportunidades respecto de esta materia de Derecho ${ }^{31}$. En todas ellas ha sostenido que para determinar la base de cálculo de las indemnizaciones legales, establecida en del artículo 172 del Código del Trabajo, los estipendios a considerar deben tener la naturaleza de remuneración. Como consecuencia de esta interpretación, la Corte ha sostenido que no se incluyen en el concepto "última remuneración mensual" la colación, la movilización, los viáticos y otros que no tienen carácter de remuneración.

En consecuencia, la Corte Suprema ha establecido una ratio decidendi en el primero de los dieciséis casos referidos a esta materia de Derecho y la ha seguido en todos los demás.

6) Procedencia de la indemnización por años de servicios establecida en el artículo $2^{\circ}$ transitorio de la ley 19.070, respecto de profesionales de la educación que renunciaron voluntariamente ajustándose a las exigencias del artículo $2^{\circ}$ transitorio de la ley 20.158.

La Corte Suprema se ha pronunciado en cincuenta y un oportunidades respecto de esta materia de Derecho ${ }^{32}$. En todos los casos ha sostenido como razón para la decisión que

\footnotetext{
31 Las dieciséis causas son las siguientes: Vega con Análisis y Servicios S.A. (2009); Alegría con Laboratorio Koni Cofarm S.A. (2010); Alarcón con Análisis y Servicios S.A. (2010); Flores y otro con Servicios Prosegur Limitada (2010); Zúñiga con Transportes Aéreos del Mercosur S.A. (2010); Fernández con Inesa Chile S.A. (2010); Monsalve con Sociedad Educacional ArabPerezLtda (2011); Berrios con Pullman cargo (2011); Rodríguez con Inversiones Alsacia S.A. (2011); Gallardo con Red Capacita S.A. (2011); Campusano con AFP Planvital S.A. (2011); Caro con Envases Del Pacifico S.A. (2011); Azócar con Sociedad Comercial Wingel Ltda. (2011); Becker con Premium Nutregg S.A. (2012); Loyola con Compass Catering S.A. (2012); y Ponce con Distribuidora de Industrias Nacionales S.A DIN (2011).

32 Las cincuenta y un causas son las siguientes: Mejias con Municipalidad de Valdivia (2009); Peralta con Municipalidad de Chiguayante (2009); Núnez Sonia y Otros con Ilustre Municipalidad de Lanco (2010); Alarcón con Municipalidad de San Pedro de la Paz (2010); Ayala con Corporación Municipal de Desarrollo Social de Iquique (2009); Cea y Otros con I. Municipalidad de Coronel (2010); Machuca con Ilustre Municipalidad de San Pedro de la Paz (2010); Ramirez con Ilustre Municipalidad de Hualpén (2010); Candia con I. Municipalidad de Yumbel (2010); Castro y Otros con Municipalidad de Colbun (2010); Espinosa con I. Municipalidad de Linares (2010); González con Ilustre Municipalidad de los Ángeles (2010); Sepúlveda con Ilustre Municipalidad de Talcahuano (2010); Uribe y Otro con I. Municipalidad de Paillaco (2010); Bustamante y Otro con I. Municipalidad de Parral (2010); Pérez y Otros con I. Municipalidad de Mariquina (2010); Avendaño y Otros con Ilustre Municipalidad de Curepto (2010); Ávila y Otros con Ilustre Municipalidad de Parral (2010); Encina y Otros contra I. Municipalidad de Yerbas (2010); Alejandrina con Ilustre Municipalidad de Talca (2010); Corvalán con Ilustre Municipalidad de Talca (2010); Libis con Municipalidad de Valdivia (2010); Lienlaf Marilafy Otras con I. Municipalidad de Mariquina (2010); Medel con Ilustre Municipalidad de Talca (2010); Rivera con Ilustre Municipalidad de Talca (2010); San Martín con Ilustre Municipalidad de Talcahuano (2010); Agurto y Otros con Ilustre Municipalidad de Cauquenes (2010); Inocencio con I. Municipalidad de Quillota (2010); Arancibia y Otros con Ilustre Municipalidad de Quillota (2010); Moya con Ilustre Municipalidad de Linares (2010); Muena y Otros con Municipalidad de Linares (2010); Concha con Ilustre Municipalidad de Constitución (2010); Silva con Municipalidad de Huechuraba (2010);
} 
no procede la indemnización por años de servicios señalada en el artículo segundo transitorio de la Ley No 19.070, cuando los docentes han renunciado voluntariamente para hacer valer la bonificación prevista en el artículo segundo transitorio de la Ley No 20.158. El fundamento de esta ratio decidendi es que aquella renuncia no es homologable jurídicamente a la causal prevista en el artículo tercero de la Ley No 19.010 y que corresponde al actual artículo 161 del Código de Trabajo, es decir necesidades de la empresa, presupuesto necesario para tener derecho a la indemnización por años de servicios.

En consecuencia, la Corte Suprema ha seguido su propio precedente en los cincuenta casos siguientes a aquel en el que se estableció la ratio decidendi aplicable a esta materia de Derecho.

7) Aplicación del Código del Trabajo a los contratos a honorarios suscritos entre un particular y una municipalidad bajo la ley 18.883 .

La Corte Suprema se ha pronunciado en dos oportunidades respecto de esta materia de Derecho ${ }^{33}$. En ambas estableció como regla que los contratos de prestación de servicios a honorarios, celebrados entre un particular y una Municipalidad, no obstante las características de cumplimiento de horario, sujeción a órdenes e instrucciones y pago de honorarios en cuotas mensuales se regulan por las normas contenidas en el propio contrato, conforme se establece en el artículo $4^{\circ}$ de la Ley $\mathrm{N}^{\circ} 18.883$, sin que le sean aplicables las disposiciones del Código del Trabajo.

En consecuencia, la Corte Suprema ha fijado y seguido la regla por ella establecida, es decir, la interpretación que previamente ha sostenido, en esta materia de Derecho.

8) Aplicación del Código del Trabajo a los contratos a honorarios suscritos entre un particular y la Administración del Estado bajo la ley 18.834 .

La Corte Suprema se ha pronunciado en cuatro oportunidades respecto de esta materia de Derecho ${ }^{34}$. En todas ellas ha aplicado como regla fundante de lo decidido que no son aplicables las normas del Código del Trabajo a quienes prestan servicios a honorarios, por cuanto esa relación se rige de acuerdo con el contrato respectivo, celebrado libremente entre las partes, conforme al artículo 10 de la ley 18.834 .

Herrera con Corporación de Desarrollo Social (2010); Aguilera con I. Municipalidad de Curicó (2010); Corvera con Ilustre Municipalidad de El Bosque (2010); Corvera con Ilustre Municipalidad de El Bosque (2010); Neira con I. Municipalidad de Hualqui (2010); Lorca y Otros con Ilustre Municipalidad de Arauco (2010); Constant y Otros con Ilustre Municipalidad de Lebu (2010); Araneda y Otros con Ilustre Municipalidad de los Álamos (2010); Fuentez y Otros con Ilustre Municipalidad de Lebu (2010); Corte Suprema, Bravo con Corporación de Desarrollo I. Municipalidad de la Reina, rol 4911-2010; Silva con Corporación de Desarrollo Social de Providencia (2010); Meza y Otros con Municipalidad de Hualañé (2010); Cárcamo con Ilustre Municipalidad de Puerto Montt (2010); Canales y otros con I. Municipalidad de San Rosendo (2010); Ahumada [esta es la carátula que aparece en la página web del Poder Judicial] (2010); Mora con Municipalidad de Chiguayante (2010); Córdova con Ilustre Municipalidad de Curicó (2010); y Cárdenas con Corporación Municipal de La Florida (2011).

33 Las dos causas son las siguientes: Lazo con Ilustre Municipalidad de Coquimbo (2009), y Torres con Ilustre Municipalidad de Coquimbo (2009).

${ }^{34}$ Las cuatro causas son las siguientes: Suazo con Fisco de Chile, Ministerio Secretaría General de Gobierno (2011); Contreras con Fondo de Solidaridad e Inversión Social (2011); Hidalgo con Corporación de Fomento de la Producción (2011); y Espinoza con Fisco de Chile, Ministerio Secretaría General de la República (2012). 
En consecuencia, en esta materia de Derecho la Corte Suprema ha seguido su propio precedente, es decir, la interpretación que previamente ha sostenido.

9) Procedencia de la sanción establecida en el artículo 162, inciso séptimo, en caso de despido indirecto (artículo 171).

La Corte Suprema se ha pronunciado en cinco oportunidades respecto de esta materia de Derecho ${ }^{35}$. En todas ellas ha establecido como regla de decisión que no procede dar aplicación al efecto sancionatorio de nulidad del despido previsto por el artículo 162, inciso séptimo, del Código del Trabajo en caso que la relación laboral haya concluido por autodespido. Esto se debe, según ha explicado, a que la sanción en comentario solo opera cuando el despido ha tenido lugar por decisión unilateral del empleador.

En consecuencia, la Corte Suprema ha establecido y seguido su propia ratio deciden$d i$ en todos los casos en que se ha tratado de esta materia de Derecho.

10) Alcance de la responsabilidad de la empresa principal respecto de las remuneraciones y demás prestaciones devengadas por la empresa contratista a sus trabajadores entre el término del contrato de trabajo y su convalidación.

La Corte Suprema se ha pronunciado en tres oportunidades respecto de esta materia de Derecho ${ }^{36}$. En la primera de ellas estableció que la empresa principal era, dependiendo del ejercicio de los derechos de información y retención, solidaria o subsidiariamente responsable de las remuneraciones y demás prestaciones devengadas a favor de los trabajadores de la empresa contratista una vez concluida la relación laboral. En las dos siguientes, en cambio, aplicó como ratio decidendi que sobre la empresa principal no recae dicha responsabilidad.

Esta es la única de las 17 materias en la que se encuentra un cambio en la orientación jurisprudencial. Sin embargo, una vez establecido dicho cambio, se ha mantenido en la siguiente decisión. En consecuencia, con la prevención indicada, resulta posible sostener que la Corte Suprema ha seguido su propio precedente, es decir, la interpretación que previamente ha sostenido, en esta materia de Derecho.

11) Interpretación de los incisos primero y segundo del artículo 510, en lo relativo al cómputo de los plazos de prescripción extintiva en materia laboral.

La Corte Suprema se ha pronunciado en cuatro oportunidades respecto de esta materia de Derecho ${ }^{37}$. En todas ellas ha aplicado la siguiente regla: la distinción respecto del cómputo de los plazos de prescripción de las acciones y derechos a que se refieren los incisos primero y segundo del artículo 510 del Código del Trabajo atiende a si el contrato de

\footnotetext{
35 Las cinco causas son las siguientes: Valdés con Administradora de Mutuos Hipotecarios del Centro S.A. (2010); Yáñez con Cúneo (2011); Ramírez y Otros con Liceo Comercial Gabriela Mistral (2011); Peralta con Corporación Municipal de Edu. Salud y Atenc. de Menores de Puente Alto (2011); y Marambio con Liceo Comercial Gabriela Mistral (2011).

36 Las tres causas son las siguientes: Solís con Diseño Paisajista (2010); Munizaga con Factor Seguridad Limitada (2011); y Castillo con Bahamonde y Cía Ltda. (2012).

37 Las cuatro causas son las siguientes: Burgos y Otros con I. Municipalidad de Lota (2010); Camaño y Otros con I. Municipalidad de Tomé (2010); Morecchio con I. Municipalidad de Tomé (2010); y Villagrán con Comercial Llanadas S.A. (2010).
} 
trabajo se encuentra vigente o ha concluido. En consecuencia, para dicho cómputo no se considera la fuente legal o contractual de los mismos.

En consecuencia, la Corte Suprema ha establecido y mantenido la misma razón para la decisión en todos los casos en que se ha tratado de la referida materia de Derecho.

12) Procedencia de la indemnización por lucro cesante, ante un despido injustificado, de conformidad con las normas del Código Civil en el proceso laboral.

La Corte Suprema se ha pronunciado en dos oportunidades respecto de esta materia de Derecho ${ }^{38}$. En ambas ha sostenido que, pese a que el lucro cesante no se contempla en el Código del Trabajo, la aplicación de las normas del resto del ordenamiento al ámbito laboral hace procedente la indemnización por este daño patrimonial de conformidad a las normas del Código Civil.

En consecuencia, la Corte Suprema ha fijado un precedente en forma de regla y la ha aplicado en los dos casos en que se ha tratado este problema de aplicación supletoria del Código Civil.

13) Alcance de la expresión "incremento del valor hora, en los años en que procedió”, para el cálculo del valor hora en el bono extraordinario anual (bono SAE).

La Corte Suprema se ha pronunciado en seis oportunidades respecto de esta materia de Derecho ${ }^{39}$. En todas ellas entendido que la expresión "incremento del valor hora, en los años en que procedió”, contenida en el artículo 9 inciso tercero de la Ley 19.933, importa descontar de los haberes destinados al pago de remuneraciones a los docentes (haberes proveídos por sucesivas leyes), los aumentos que ha experimentado el valor hora cronológica desde el año 1998 en adelante, en virtud de la ley 19.598, de 1999. Se rechaza, en consecuencia, deducir los incrementos experimentados por el valor hora desde la dictación de la ley 20.158, de 2006. De este modo, solo si tras la deducción de que se viene tratando existen excedentes, los mismos deberán ser distribuidos como bono extraordinario anual (bono SAE) entre los docentes.

En consecuencia, la Corte Suprema ha seguido su propio precedente, es decir, la interpretación que previamente ha sostenido, en esta materia de Derecho.

14) Aplicabilidad de la fórmula de cálculo del bono extraordinario anual (bono SAE) a los docentes del sector municipal.

La Corte Suprema se ha pronunciado en cuatro oportunidades respecto de esta materia de Derecho ${ }^{40}$. En todos ellos ha sostenido que la fórmula de cálculo del bono ex-

\footnotetext{
38 Las dos causas son las siguientes: Medina con Sistemas Internacionales de Calidad Ltda. y Otro (2010); y Campos y Otros con Empresa de Montajes Industriales Salfa S.A. (2011).

39 Los seis casos son los siguientes: Domke con Ilustre Municipalidad de Puerto Montt (2011); Bravo y Otros con Ilustre Municipalidad de Osorno (2011); Parra y Otros con Ilustre Municipalidad de Temuco (2011); Aguirre con Corporación Municipal de Desarrollo Social de Antofagasta (2012); Pereira con Ilustre Municipalidad de San Esteban (2012); y Poblete y Otros con Corporación de Desarrollo de la comuna de San Vicente de Tagua Tagua (2012).

40 Las cuatro causas son las siguientes: Parra y Otros con Ilustre Municipalidad de Temuco (2011); Cutiño con Ilustre Municipalidad de Puerto Aysén (2011); Moya con Ilustre Municipalidad de Frutillar (2011); y Contreras con Ilustre Municipalidad de Puerto Montt (2012).
} 
traordinario anual (que incluye entre los descuentos que se deben aplicar a los excedentes, el incremento del valor hora en los años anteriores, de conformidad con lo establecido en el inciso tercero del artículo 9 de la Ley 19.933), resulta aplicable a los profesionales de la educación pertenecientes a una dotación del sector municipal.

En consecuencia, la Corte Suprema ha fijado una determinada manera de interpretar esta materia de Derecho y la ha aplicado en todos los casos en que se ha tratado de aquella.

15) Aplicabilidad del procedimiento de Tutela de Derechos a funcionarios públicos "a contrata".

La Corte Suprema se ha pronunciado en tres oportunidades respecto de esta materia de Derecho ${ }^{41}$. Al respecto ha establecido como ratio decidendi que el procedimiento de Tutela de Derechos contemplado en el libro V del Código del Trabajo no es aplicable a los funcionarios públicos a contrata, de modo que, en razón de la materia, los Tribunales Laborales son absolutamente incompetentes. La razón en que se ha fundado esta decisión es que la relación de tales trabajadores con el Fisco no es de carácter laboral, como lo exigen los requisitos de procedencia de la acción de tutela.

De este modo, la Corte Suprema ha aplicado la misma ratio decidendi en todos los casos que han versado sobre esta aplicación supletoria del Código del Trabajo al ámbito público.

16) Aplicación de la ficción legal del artículo 168 inciso cuarto del Código del Trabajo, para los efectos de la procedencia de la indemnización adicional que establece el artículo 87 del Estatuto Docente, que exige que los términos de los servicios se verifique conforme al artículo 161 del Código del Trabajo.

La Corte Suprema se ha pronunciado en tres oportunidades respecto de esta materia de Derecho ${ }^{42}$. En todas ellas ha aplicado como razón para lo decidido que la indemnización adicional establecida en el artículo 87 de la ley 19.070 (Estatuto docente) solo procede cuando el empleador ha puesto término al contrato de trabajo por necesidades de la empresa y no cuando esta causal se aplica de manera ficta de conformidad con lo estatuido en el artículo 168, inciso cuarto, del Código del Trabajo. La justificación ofrecida para sostener esta ratio decidendi es que esta ficción, por su naturaleza, no puede aplicarse de forma amplia, de modo no tiene aptitud para hacer procedente la indemnización adicional dispuesta en el artículo 87 del Estatuto Docente.

Al respecto conviene recordar que el artículo 87 del Estatuto Docente obliga al pago de una indemnización adicional, equivalente al total de las remuneraciones que habría tenido derecho a percibir el profesional de la educación si su contrato hubiese durado hasta el término del año laboral en curso, cuando fuere el empleador quien pusiere término al contrato de trabajo de acuerdo al artículo 161 del Código del Trabajo. Por su parte, el artículo 168 inciso cuarto del Código del ramo previene que si el juez estableciera que la aplicación

\footnotetext{
41 Los tres casos son los siguientes: Vallejos y Otro con Fisco de Chile (2011); Castillo con Intendencia Regional de la Araucanía (2011); y Gasca con Zúñiga (2011).

42 Las tres causas son las siguientes: Cabello con Cáceres (2011); Soto con Colegio Misionero de Agostini (2011); y Castillo con Jara (2012).
} 
de una o más de las causales de terminación del contrato establecidas en los artículos 159 y 160 no ha sido acreditada, se entenderá que el término del contrato se ha producido por aplicación del artículo 161 .

En consecuencia, la Corte Suprema ha seguido su propio precedente, es decir, la interpretación que previamente ha sostenido, en todas las causas referidas a esta materia de Derecho.

17) Poder liberatorio del finiquito válidamente celebrado.

La Corte Suprema se ha pronunciado en dos ocasiones sobre esta materia de Derecho $^{43}$. En ambos ha sostenido que el finiquito válidamente celebrado entre empleador y trabajador tiene pleno poder liberatorio en todo aquello que es objeto de dicho instrumento, sin que pueda obstar a esta conclusión la posible aplicación del principio de la realidad porque el trabajador luego de suscribir dicho finiquito continuó prestando los mismos servicios para el mismo empleador.

De este modo, la Corte Suprema aparece manteniendo la ratio decidendi instalada en el siguiente caso en el que se trató de la misma materia de Derecho objeto del juicio.

\section{CONCLUSIONES}

La pregunta que ha pretendido responder esta investigación, esto es, si existe seguimiento interno e institucional de los precedentes establecidos mediante el recurso de unificación de jurisprudencia laboral por parte de la Corte Suprema, debe ser respondida afirmativamente. En efecto, se ha verificado que el máximo tribunal del Poder Judicial ha aplicado exactamente la misma ratio decidendi en cada una de las materias de Derecho del Trabajo que han sido sometidas a su conocimiento en virtud de los recursos de unificación de jurisprudencia deducidos entre el 30 de marzo de 2008 y el 29 de marzo de 2012. Solo en un caso se produjo un giro en la orientación jurisprudencial, cambio que luego fue seguido.

Tal hallazgo es, sin duda, sorprendente y, por sobre todo, inédito. En efecto, es la primera vez que se acredita empíricamente que un intento legislativo de uniformar la jurisprudencia, en este caso en el ámbito laboral, tuvo éxito. La casación civil nunca logró este objetivo antes de la reforma aplicada en el año 1995 al Código de Procedimiento Civil ${ }^{44}$, y no existe evidencia científica que demuestre un cambio tras dicha reforma. En materia

${ }_{43}$ Las dos causas son las siguientes: Fuentealba Candia Lorena con I. Municipalidad San José (2009); y Salgado con Toledo y otros (2010).

${ }^{44}$ Como se sabe, mediante la Ley 19.374, de 1995, se modificó el artículo 780 del Código de Procedimiento Civil, incorporándose la posibilidad de solicitar que el pleno de la Corte Suprema se pronuncie respecto de las diversas interpretaciones que este mismo tribunal ha dado a una determinada materia de Derecho. El objetivo de esta reforma fue alcanzar algo que hasta esa fecha no se había logrado y que Raúl Tavolari expresaba del siguiente modo en 1996: con esta reforma "se busca la uniformidad de la jurisprudencia Suprema, aspiración reiteradamente perseguida por el legislador en procura de la certeza y la seguridad jurídicas". En el mismo sentido, Mario Mosquera y Cristian Maturana explican que con esta reforma se pretendió alcanzar el propósito que tuvo el legislador al incorporar la casación en el fondo en el ordenamiento jurídico chileno, esto es, obtener la uniformidad en la aplicación de la ley. Al efecto ver Tavolari (1996) pp. 73 y 74, y Mosquera y Maturana (2012) pp. 290 a 292. 
penal, por su parte, los estudios disponibles indican que la pretensión uniformadora fue simplemente un fracaso ${ }^{45}$. De este modo, conviene reiterarlo, el recurso de unificación de jurisprudencia ha significado, en los hechos, la introducción de una práctica de seguimiento del precedente en el ámbito laboral por parte de la Corte Suprema.

Este seguimiento del propio precedente es tan evidente que las diversas sentencias que conforman un determinado universo útil presentan, en la mayoría de los casos, una transcripción de la fundamentación ofrecida en sentencias anteriores, incluyendo por cierto la respectiva ratio decidendi. Esta reiteración de lo considerativo en las diversas sentencias que tratan de una misma materia objeto del juicio no debe ser mirado como un defecto jurisprudencial. Lejos de ello, se trata más bien de uno de los efectos que en el ámbito de la economía procesal genera el seguimiento del precedente.

Junto con la conclusión expresada, los datos arrojados por esta investigación permiten generar ciertas hipótesis que en todo caso deben ser confirmadas. Una de ellas, y ciertamente la más evidente, es que la sala laboral de la Corte Suprema presenta una inclinación a favor de las pretensiones de los empleadores y del Estado. Una segunda hipótesis es que el seguimiento del precedente parece desincentivar la litigación en aquellas materias de Derecho en las que existen precedentes consolidados. En fin, y sin ánimo de ser exhaustivos, la Corte Suprema ha generado causales de inadmisibilidad, y por tanto una elevada selectividad, al margen de lo establecido por la ley.

Además, la presente investigación ha generado nuevas preguntas que deben ser enfrentadas. La principal y de más urgente respuesta es la siguiente: ¿qué factores inciden en que la Corte Suprema presente tan estricto y extraordinario seguimiento del precedente en el ámbito laboral? Una segunda interrogante igualmente importante puede ser formulada del siguiente modo: ¿existe comportamiento precedencial por parte de los Ministros que integran la sala laboral? En otras palabras, ¿están dispuestos a modificar sus propias preferencias interpretativas para sumarse a la posición adoptada en el precedente?

Tales hipótesis y preguntas habrán de ser objeto de nuevas investigaciones.

\section{BIBLIOGRAFÍA CITADA}

Comanducci, Paolo (1999): "Igualdad liberal", Revista juridica de la Universidad de Palermo, año 3, $\mathrm{N}^{\circ}$ 2: pp. 81-90.

Couso, Jaime, y MerA, Jorge (2011): "El rol uniformador de la jurisprudencia de la sala penal de la Corte Suprema. Estudio Empírico", en Couso, Jaime, y Mera, Jorge, Precedentes y justicia penal (Santiago de Chile, Ediciones Universidad Diego Portales) pp. 97-195.

Couso Salas, Jaime (2007): "El rol uniformador de la jurisprudencia de la Sala Penal de la Corte Suprema: Anatomía de un fracaso", Revista de Derecho (Valdivia), Vol. XX, No 2: pp. 147-172.

Cross, Rupert (1977): Precedent in English law (Oxford, Charendon Press, Third edition). Duxbury, Neil (2008): The nature and authority of precedent (United Kingdom, Cambridge University Press).

$45 \mathrm{Al}$ respecto ver Couso (2007) pp. 147-172. 
FÁBregA, Hugo (2010): “Asignaciones de colación y movilización. Unificación jurisprudencial en materia laboral”, Actualidad jurídica Universidad del Desarrollo, año 11, $\mathrm{N}^{\circ} 22$ : pp. 527-532.

HaLim, Fernando (2011): El recurso de unificación de jurisprudencia laboral. Tomo I (Santiago de Chile, Puntolex y Thomson Reuters).

Halpern, Cecily, y Humeres, Héctor (2010): "La intervención de la Corte Suprema en la nueva justicia del trabajo: el recurso de unificación de jurisprudencia”, Actualidad Jurídica Universidad del Desarrollo, Año XI, N²1, enero 2010: pp. 345-374.

LANATA, Gabriela (2011): El sistema de recursos en el proceso laboral chileno (Santiago, AbeledoPerrot y Thomson Reuters, segunda edición).

Llewellyng, Karl (1989): The case law system in America. Translate from the German by Michael Ansaldi (Chicago, The University of Chicago Press).

MacCormick, Neil, y Summers, Robert S., eds. (1997): Interpreting precedents. A comparative study (Aldershot-Brookfield, Ashgate Dartmouth).

Mosquera, Mario, y Maturana, Mario (2012): Los recursos procesales (Santiago de Chile, Editorial Jurídica de Chile, segunda edición).

Mendonca, Daniel, y Guibourg, Ricardo A. (2004): La odisea constitucional. Constitución, teoría y método (Madrid, Marcial Pons).

Odette, Camila (2013): "Recurso de unificación de jurisprudencia desde el Derecho comparado", Actualidad Juridica Universidad del Desarrollo, año XIV, No 27: pp. 437-473.

Peczenik, Aleksander (1997): “The binding force of precedent”, en MacCormick, Neil, y Summers, Robert S. (eds.), Interpreting precedents. A comparative study (Aldershot-Brookfield, Ashgate Dartmouth) pp. 461-479.

Siltala, Raimo (2000): A theory of precedent. From analytical positivism to a post-analytical philosophy of law (Oregon, Hart Publishing Oxford and Portland).

Tavolari, Raúl (1996): Recursos de casación y queja: Nuevo régimen (Santiago de Chile, Editorial Jurídica Conosur Ltda.).

WhitTAKER, Simon (2008): "El precedente en el derecho inglés: una visión desde la ciudadela” (Trad. Cristián Banfi del Río), Revista Chilena de Derecho, vol. 35, Nº 1: pp. 37-83.

\section{DOCUMENTOS EN FORMATO ELECTRÓNICO}

Biblioteca del Congreso Nacional (2008): "Historia de la ley 20.260". Modifica el Libro IV del Código del Trabajo y la ley 20.087, que establece un nuevo procedimiento laboral” Disponible en: http://www.leychile.cl/Consulta/portada_hl?tipo_ norma=XX1\&nro_ley=20260\&anio=2013. [Fecha de visita: 25 de agosto de 2013].

\section{NORMAS LEGALES CITADAS}

Código del Trabajo de Chile, decreto con fuerza de ley $\mathrm{N}^{\circ} 1$, del Ministerio del Trabajo y Previsión Social, Fija el texto refundido, coordinado y sistematizado del Código del Trabajo. Diario Oficial de 16 de enero de 2003. 
Ley No 19.374 (1995): Modifica Códigos Orgánico de Tribunales, de Procedimiento Civil y de Procedimiento Penal, en lo relativo a organización y funcionamiento de la Corte Suprema, recurso de queja y recurso de casación. Disponible en: http://www.leychile.cl/ Navegar?idLey=19374\&idVersion=1995-02-18. [fecha consulta: 3 de marzo de 2014]. Diario Oficial de 18 de febrero de 1995.

\section{SENTENCIAS CITADAS}

AÑo 2009

Fuentealba Candia Lorena con I. Municipalidad San José (2009): Corte Suprema, 27 de octubre de 2009 (recurso de unificación de jurisprudencia, rol 5816-2009).

Lazo con Ilustre Municipalidad de Coquimbo (2009): Corte Suprema, 10 de noviembre de 2009 (recurso de unificación de jurisprudencia rol 6335-2009).

Torres con Ilustre Municipalidad de Coquimbo (2009): Corte Suprema, 10 de diciembre de 2009 (recurso de unificación de jurisprudencia rol 6781-2009).

\section{AÑo 2010}

Mejías con Municipalidad de Valdivia (2010): Corte Suprema, 31 de marzo de 2010 (recurso de unificación de jurisprudencia rol 8809-2009).

Saldaña con Interagro Comercio y Ganado S.A. (2010): Corte Suprema, 8 de abril de 2010 (recurso de unificación de jurisprudencia rol 9265-2009).

Núñez con Sociedad Contractual Minera Tambillos (2010): Corte Suprema, 20 de abril de 2010 (recurso de unificación de jurisprudencia rol 852-2010).

Peralta con Municipalidad de Chiguayante (2010): Corte Suprema, 21 de abril de 2010 (recurso de unificación de jurisprudencia rol 9024-2009).

Vega con Análisis y Servicios S.A. (2010): Corte Suprema, 21 de abril de 2010 (recurso de unificación de jurisprudencia rol 9603-2009).

Núñez Sonia y Otros con Ilustre Municipalidad de Lanco (2010): Corte Suprema, 22 de abril de 2010 (recurso de unificación de jurisprudencia rol 627-2010).

Alarcón con Municipalidad de San Pedro de la Paz (2010): Corte Suprema, 28 de abril de 2010 (recurso de unificación de jurisprudencia rol 212-2010).

Ayala con Corporación Municipal de Desarrollo Social de Iquique (2010): Corte Suprema, 28 de abril de 2010 (recurso de unificación de jurisprudencia rol 7930-2009).

Cea y Otros con I. Municipalidad de Coronel (2010): Corte Suprema, 9 de junio de 2010 (recurso de unificación de jurisprudencia rol 1167-2010).

Machuca con Ilustre Municipalidad de San Pedro de la Paz (2010): Corte Suprema, 9 de junio de 2010 (recurso de unificación de jurisprudencia rol 171-2010).

Ramírez con Ilustre Municipalidad de Hualpén (2010): Corte Suprema, 9 de junio de 2010 (recurso de unificación de jurisprudencia rol 915-2010).

Candia con I. Municipalidad de Yumbel (2010): Corte Suprema, 15 de junio de 2010 (recurso de unificación de jurisprudencia rol 1346-2010).

Castro y Otros con Municipalidad de Colbún (2010): Corte Suprema, 15 de junio de 2010 (recurso de unificación de jurisprudencia rol 1984-2010). 
Espinosa con I. Municipalidad de Linares (2010): Corte Suprema, 15 de junio de 2010 (recurso de unificación de jurisprudencia rol 3357-2010).

González con Ilustre Municipalidad de los Ángeles (2010): Corte Suprema, 15 de junio de 2010 (recurso de unificación de jurisprudencia rol 2975-2010).

Sepúlveda con Ilustre Municipalidad de Talcahuano (2010): Corte Suprema, 15 de junio de 2010 (recurso de unificación de jurisprudencia rol 1312-2010).

Uribe y Otro con I. Municipalidad de Paillaco (2010): Corte Suprema, 15 de junio de 2010 (recurso de unificación de jurisprudencia rol 1985-2010).

Bustamante y Otro con I. Municipalidad de Parral (2010): Corte Suprema, 16 de junio de 2010 (recurso de unificación de jurisprudencia rol 1584-2010).

Pérez y Otros con I. Municipalidad de Mariquina (2010): Corte Suprema, 24 de junio de 2010 (recurso de unificación de jurisprudencia rol 2419-2010).

Avendaño y Otros con Ilustre Municipalidad de Curepto (2010): Corte Suprema, 29 de junio de 2010 (recurso de unificación de jurisprudencia rol 1349-2010).

Ávila y Otros con Ilustre Municipalidad de Parral (2010): Corte Suprema, 29 de junio de 2010 (recurso de unificación de jurisprudencia rol 1954-2010).

Encina y Otros contra I. Municipalidad de Yerbas (2010): Corte Suprema, 29 de junio de 2010 (recurso de unificación de jurisprudencia rol 1586-2010).

Alejandrina con Ilustre Municipalidad de Talca (2010): Corte Suprema, 30 de junio de 2010 (recurso de unificación de jurisprudencia rol 1392-2010).

Corvalán con Ilustre Municipalidad de Talca (2010): Corte Suprema, 30 de junio de 2010 (recurso de unificación de jurisprudencia rol 1345-2010).

Libis con Municipalidad de Valdivia (2010): Corte Suprema, 30 de junio de 2010 (recurso de unificación de jurisprudencia rol 1639-2010).

Lienlaf Marilafy Otras con I. Municipalidad de Mariquina (2010): Corte Suprema, 30 de junio de 2010 (recurso de unificación de jurisprudencia rol 629-2010).

Medel con Ilustre Municipalidad de Talca (2010): Corte Suprema, 30 de junio de 2010 (recurso de unificación de jurisprudencia rol 1489-2010).

Rivera con Ilustre Municipalidad de Talca (2010): Corte Suprema, 30 de junio de 2010 (recurso de unificación de jurisprudencia rol 1491-2010).

San Martín con Ilustre Municipalidad de Talcahuano (2010): Corte Suprema, 30 de junio de 2010 (recurso de unificación de jurisprudencia rol 2454-2010).

Agurto y Otros con Ilustre Municipalidad de Cauquenes (2010): Corte Suprema, 13 de julio de 2010 (recurso de unificación de jurisprudencia rol 3352-2010).

Inocencio con I. Municipalidad de Quillota (2010): Corte Suprema, 13 de julio de 2010 (recurso de unificación de jurisprudencia rol 3609-2010).

Arancibia y Otros con Ilustre Municipalidad de Quillota (2010): Corte Suprema, 28 de julio de 2010 (recurso de unificación de jurisprudencia rol 3488-2010).

Moya con Ilustre Municipalidad de Linares (2010): Corte Suprema, 28 de julio de 2010 (recurso de unificación de jurisprudencia rol 3718-2010).

Muena y Otros con Municipalidad de Linares (2010): Corte Suprema, 28 de julio de 2010 (recurso de unificación de jurisprudencia rol 1959-2010). 
Concha con Ilustre Municipalidad de Constitución (2010): Corte Suprema, 4 de agosto de 2010 (recurso de unificación de jurisprudencia rol 2578-2010).

Silva con Municipalidad de Huechuraba (2010): Corte Suprema, 2 de septiembre de 2010 (recurso de unificación de jurisprudencia rol 3991-2010).

Herrera con Corporación de Desarrollo Social (2010): Corte Suprema, 9 de septiembre de 2010 (recurso de unificación de jurisprudencia rol 3846-2010).

Aguilera con I. Municipalidad de Curicó (2010): Corte Suprema, 14 de septiembre de 2010 (recurso de unificación de jurisprudencia rol 3358-2010).

Corvera con Ilustre Municipalidad de El Bosque (2010): Corte Suprema, 16 de septiembre de 2010 (recurso de unificación de jurisprudencia rol 3292-2010).

Corvera con Ilustre Municipalidad de El Bosque (2010): Corte Suprema, 16 de septiembre de 2010 (recurso de unificación de jurisprudencia rol 3293-2010).

Neira con I. Municipalidad de Hualqui (2010): Corte Suprema, 16 de septiembre de 2010 (recurso de unificación de jurisprudencia rol 3013-2010).

Lorca y Otros con Ilustre Municipalidad de Arauco (2010): Corte Suprema, 30 de septiembre de 2010 (recurso de unificación de jurisprudencia rol 5062-2010).

Burgos y Otros con I. Municipalidad de Lota (2010): Corte Suprema, 12 de octubre de 2010 (recurso de unificación de jurisprudencia rol 4510-2010).

Villanueva con Fisco de Chile Armada de Chile (2010): Corte Suprema, 26 de octubre de 2010 (recurso de unificación de jurisprudencia rol 5447-2010).

Alegría con Laboratorio Koni Cofarm S.A. (2010): Corte Suprema, 28 de octubre de 2010 (recurso de unificación de jurisprudencia rol 4196-2010).

Constant y Otros con Ilustre Municipalidad de Lebu (2010): Corte Suprema, 3 de noviembre de 2010 (recurso de unificación de jurisprudencia rol 5010-2010).

Araneda y Otros con Ilustre Municipalidad de los Álamos (2010): Corte Suprema, 9 de noviembre de 2010 (recurso de unificación de jurisprudencia rol 5833-2010).

Pereira con Consorcio RDTC S.A. (2010): Corte Suprema, 10 de noviembre de 2010 (recurso de unificación de jurisprudencia rol 5451-2010).

Fuentez y Otros con Ilustre Municipalidad de Lebu (2010): Corte Suprema, 11 de noviembre de 2010 (recurso de unificación de jurisprudencia rol 5011-2010).

Bravo con Corporación de Desarrollo I. Municipalidad de la Reina (2010): Corte Suprema, 15 de noviembre de 2010 (recurso de unificación de jurisprudencia rol 4911-2010).

Camaño y Otros con I. Municipalidad de Tomé (2010): Corte Suprema, 23 de noviembre de 2010 (recurso de unificación de jurisprudencia rol 6455-2010).

Silva con Corporación de Desarrollo Social de Providencia (2010): Corte Suprema, 26 de noviembre de 2010 (recurso de unificación de jurisprudencia rol 5835-2010).

Alarcón con Análisis y Servicios S.A. (2010): Corte Suprema, 30 de noviembre de 2010 (recurso de unificación de jurisprudencia rol 6074-2010).

Meza y Otros con Municipalidad de Hualañé (2010): Corte Suprema, 9 de diciembre de 2010 (recurso de unificación de jurisprudencia rol 6763-2010).

Cárcamo con Ilustre Municipalidad de Puerto Montt (2010): Corte Suprema, 10 de diciembre de 2010 (recurso de unificación de jurisprudencia rol 5132-2010). 
AÑo 2011

Flores y otro con Servicios Prosegur Limitada (2011): Corte Suprema, 6 de enero de 2011 (recurso de unificación de jurisprudencia rol 5881-2010).

Zúñiga con Transportes Aéreos del Mercosur S.A. (2011): Corte Suprema, 26 de enero de 2011 (recurso de unificación de jurisprudencia rol 7362-2010).

A.F.P. Provida con Román (2011): Corte Suprema, 27 de enero de 2011 (recurso de unificación de jurisprudencia rol 4751-2010).

Gómez con ING AFP Capital S.A. (2011): Corte Suprema, 27 de enero de 2011 (recurso de unificación de jurisprudencia rol 6019-2010).

Prado con ING AFP Capital S.A. (2011): Corte Suprema, 27 de enero de 2011 (recurso de unificación de jurisprudencia rol 6552-2010).

Morecchio con I. Municipalidad de Tomé (2011): Corte Suprema, 11 de marzo de 2011 (recurso de unificación de jurisprudencia rol 6936-2010).

Canales y otros con I. Municipalidad de San Rosendo (2011): Corte Suprema, 23 de marzo de 2011 (recurso de unificación de jurisprudencia rol 4371-2010).

Valdés con Administradora de Mutuos Hipotecarios del Centro S.A. (2011): Corte Suprema, 24 de marzo de 2011 (recurso de unificación de jurisprudencia rol 6510-2010).

Villagrán con Comercial Llanadas S.A. (2011): Corte Suprema, 24 de marzo de 2011 (recurso de unificación de jurisprudencia rol 7104-2010).

Reyes con A.F.P. Próvida S.A. (2011): Corte Suprema, 25 de marzo de 2011 (recurso de unificación de jurisprudencia rol 6101-2010).

Cabrera con A.F.P. Próvida S.A. (2011): Corte Suprema, 28 de marzo de 2011 (recurso de unificación de jurisprudencia rol 6114-2010).

Pereira con A.F.P. Próvida S.A. (2011): Corte Suprema, 28 de marzo de 2011 (recurso de unificación de jurisprudencia rol 6115-2010).

Ahumada [esta es la carátula que aparece en la página web del Poder Judicial] (2011): Corte Suprema, 29 de marzo de 2011 (recurso de unificación de jurisprudencia rol 78282010).

Cáceres con ING AFP Capital S.A. (2011):Corte Suprema, 29 de marzo de 2011 (recurso de unificación de jurisprudencia rol 6777-2010).

Mora con Municipalidad de Chiguayante (2011): Corte Suprema, 29 de marzo de 2011 (recurso de unificación de jurisprudencia rol 6973-2010).

Monroy y otra con AFP Hábitat S.A. (2011): Corte Suprema, 31 de marzo de 2011 (recurso de unificación de jurisprudencia rol 6450-2010).

Solís con Diseño Paisajista (2011): Corte Suprema, 31 de Marzo de 2011 (recurso de unificación de jurisprudencia rol 7502-2010).

Fernández con Inesa Chile S.A. (2011): Corte Suprema, 12 de abril de 2011 (recurso de unificación de jurisprudencia rol 8155-2010).

Medina con Sistemas Internacionales de Calidad Ltda. y Otro (2011): Corte Suprema, 29 de abril de 2011 (recurso de unificación de jurisprudencia rol 8279-2010).

Orellana con Ilustre Municipalidad de El Monte (2011): Corte Suprema, 29 de abril de 2011 (recurso de unificación de jurisprudencia rol 7154-2010). 
Córdova con Ilustre Municipalidad de Curicó (2011): Corte Suprema, 13 de mayo de 2011 (recurso de unificación de jurisprudencia rol 8859-2010).

Rencoret y Otro con AFP Provida S.A. (2011): Corte Suprema, 13 de mayo de 2011 (recurso de unificación de jurisprudencia rol 7208-2010).

Salgado con Toledo y otros (2011): Corte Suprema, 31 de mayo de 2011 (recurso de unificación de jurisprudencia, rol 8316-2010).

Caro y Otros con AFP Provida S.A. (2011): Corte Suprema, 3 de junio de 2011 (recurso de unificación de jurisprudencia rol 6932-2010).

Yáñez con Cúneo (2011): Corte Suprema, 6 de junio de 2011 (recurso de unificación de jurisprudencia rol 704-2011).

Araya con Bodega La Esperanza Viñedos Errázuriz Ovalle S.A. (2011): Corte Suprema, 16 de junio de 2011 (recurso de unificación de jurisprudencia rol 10120-2010).

Soza con Televisión Nacional de Chile (2011): Corte Suprema, 16 de junio de 2011 (recurso de unificación de jurisprudencia rol 205-2011).

Sindicato de Trabajadores de la AFP Provida S.A. con AFP Provida S.A. (2011): Corte Suprema, 29 de junio de 2011 (recurso de unificación de jurisprudencia rol 1117-2011).

Acosta y Otros con Sociedad Depetris Deflorian Hnos. Ltda. (2011): Corte Suprema, 30 de junio de 2011 (recurso de unificación de jurisprudencia rol 116-2011).

Valenzuela con AFP Capital S.A. (2011): Corte Suprema, 8 de julio de 2011 (recurso de unificación de jurisprudencia rol 8860-2010).

Munizaga con Factor Seguridad Limitada (2011): Corte Suprema, 1 de agosto de 2011 (recurso de unificación de jurisprudencia rol 9669-2011).

Vallejos y Otro con Fisco de Chile (2011): Corte Suprema, 8 de agosto de 2011 (recurso de unificación de jurisprudencia rol 8680-2011).

Araya con Monte Nevado Ingeniería y Otros (2011): Corte Suprema, 10 de agosto de 2011 (recurso de unificación de jurisprudencia rol 9375-2010).

Cárdenas con Corporación Municipal de La Florida (2011): Corte Suprema, 29 de agosto de 2012 (recurso de unificación de jurisprudencia rol 10066-2011).

Osses y Otros con AFP Habitat S.A. (2011): Corte Suprema, 29 de agosto de 2011 (recurso de unificación de jurisprudencia rol 470-2011).

Castillo con Intendencia Regional de la Araucanía (2011): Corte Suprema, 5 de octubre de 2011 (recurso de unificación de jurisprudencia rol 1972-2011).

Tudela con Corporación Municipal de Servicio y Desarrollo de Maipú (2011): Corte Suprema, 27 de octubre de 2011 (recurso de unificación de jurisprudencia rol 70-2011).

Abello con Librería Giorgio Temuco y CIA Limitada (2011): Corte Suprema, 14 de noviembre de 2011 (recurso de unificación de jurisprudencia rol 1391-2011).

Monsalve con Sociedad Educacional ArabPerezLtda (2011): Corte Suprema, 15 de noviembre de 2011 (recurso de unificación de jurisprudencia rol 3169-2011).

Cabello con Cáceres (2011): Corte suprema, 17 de noviembre de 2011 (recurso de unificación de jurisprudencia rol 3488-2011).

Berríos con Pullman cargo (2011): Corte Suprema, 6 de diciembre de 2011 (recurso de unificación de jurisprudencia rol 3168-2011). 
Boasso con Rosa (2011): Corte Suprema, 15 de diciembre de 2011 (recurso de unificación de jurisprudencia rol 4584-2011).

Dussuel con Colegio San Bartolomé De Nos S.A. (2011): Corte Suprema, 31 de enero de 2012 (recurso de unificación de jurisprudencia rol 5964-2011).

Alarcón con Administradora de Fondos de Pensiones Capital S.A. (2011): Corte Suprema, 16 de diciembre de 2011 (recurso de unificación de jurisprudencia rol 1863-2011).

Sindicato Unificado de Trabajadores de Isapre Banmédica S.A. con Isapre Banmédica S.A. (2011): Corte Suprema, 16 de diciembre de 2011 (recurso de unificación de jurisprudencia rol 2739-2011).

AÑo 2012

Rodríguez con Inversiones Alsacia S.A. (2012): Corte Suprema, 27 de enero de 2012 (recurso de unificación de jurisprudencia rol 4735-2011).

Campos y Otros con Empresa de Montajes Industriales Salfa S.A. (2012): Corte Suprema, 30 de enero de 2012 (recurso de unificación de jurisprudencia rol 4259-2011).

Gallardo con Red Capacita S.A. (2012): Corte Suprema, 24 de abril de 2012 (recurso de unificación de jurisprudencia rol 5843-2011).

Suazo con Fisco de Chile, Ministerio Secretaría General de Gobierno (2012): Corte Suprema, 25 de abril de 2012 (recurso de unificación de jurisprudencia rol 5839-2011).

Aravena y Otros con VTR Global Com S.A. (2012): Corte Suprema, 17 de mayo de 2012 (recurso de unificación de jurisprudencia rol 8788-2011).

Contreras con Fondo de Solidaridad e Inversión Social (2012): Corte Suprema, 25 de mayo de 2012 (recurso de unificación de jurisprudencia rol 8118-2011).

Gonzáles y Otros con AFP Provida S.A. (2012): Corte Suprema, 6 de junio de 2012 (recurso de unificación de jurisprudencia rol 8322-2011).

Campusano con AFP Planvital S.A. (2012): Corte Suprema, 8 de junio de 2012 (recurso de unificación de jurisprudencia rol 8504-2011).

Caro con Envases del Pacífico S.A. (2012): Corte Suprema, 14 de junio de 2012 (recurso de unificación de jurisprudencia rol 9242-2011).

Ramírez y Otros con Liceo Comercial Gabriela Mistral (2012): Corte Suprema, 22 de junio de 2012 (recurso de unificación de jurisprudencia rol 8488-2011).

Hidalgo con Corporación de Fomento de la Producción (2012): Corte Suprema., 27 de junio de 2012 (recurso de unificación de jurisprudencia rol 5544-2011).

Peralta con Corporación Municipal de Edu. Salud y Atenc. de Menores de Puente Alto (2012): Corte Suprema, 3 de agosto de 2012 (recurso de unificación de jurisprudencia rol 10266-2011).

Parada con AFP Capital S.A. (2012): Corte Suprema, 8 de agosto de 2012 (recurso de unificación de jurisprudencia rol 10713-2011).

Kerbernhard con Recaudación y Cobranzas S.A. (2012): Corte Suprema, 9 de agosto de 2012 (recurso de unificación de jurisprudencia rol 9579-2011).

Azocar con Sociedad Comercial Wingel Ltda. (2012): Corte Suprema, 10 de agosto de 2012 (recurso de unificación de jurisprudencia rol 9838-2011). 
Marambio con Liceo Comercial Gabriela Mistral (2012): Corte Suprema, 17 de agosto de 2012 (recurso de unificación de jurisprudencia rol 8892-2011).

Soto con Colegio Misionero de Agostini (2012): Corte Suprema, 17 de agosto de 2012 (recurso de unificación de jurisprudencia rol 11875-2011).

Becker con Premium Nutregg S.A. (2012): Corte Suprema, 21 de agosto de 2012 (recurso de unificación de jurisprudencia rol 361-2012).

Loyola con Compass Catering S.A. (2012): Corte Suprema, 21 de agosto de 2012 (recurso de unificación de jurisprudencia rol 208-2012).

Irazzoky con Comercial Rey S.A. (2012): Corte Suprema, 24 de agosto de 2012 (recurso de unificación de jurisprudencia rol 11873-2011).

Ponce con Distribuidora de Industrias Nacionales S.A DIN (2012): Corte Suprema, 24 de agosto de 2012 (recurso de unificación de jurisprudencia rol 11655-2011).

Orrego con Empresa Periodistica La Cuarta S.A. (2012): Corte Suprema, 29 de agosto de 2012 (recurso de unificación de jurisprudencia rol 8989-2011).

Espinoza con Fisco de Chile, Ministerio Secretaría General de la República (2012): Corte Suprema, 30 de agosto de 2012 (recurso de unificación de jurisprudencia rol 462-2012).

Domke con Ilustre Municipalidad de Puerto Montt (2012): Corte Suprema, 31 de agosto de 2012 (recurso de unificación de jurisprudencia rol 10871-2011).

Bravo y Otros con Ilustre Municipalidad de Osorno (2012): Corte Suprema, 6 de septiembre de 2012 (recurso de unificación de jurisprudencia rol 8035-2011).

Parra y Otros con Ilustre Municipalidad de Temuco (2012): Corte Suprema, 6 de septiembre de 2012 (recurso de unificación de jurisprudencia rol 7871-2011).

Aguirre con Corporación Municipal de Desarrollo Social de Antofagasta (2012): Corte Suprema, 12 de septiembre de 2012 (recurso de unificación de jurisprudencia rol 589-2012).

Cutiño con Ilustre Municipalidad de Puerto Aysén (2011): Corte Suprema, 26 de septiembre de 2012 (RUJ rol 8780-2011).

Gasca con Zuñiga (2012): Corte Suprema, 3 de octubre de 2012 (recurso de unificación de jurisprudencia rol 12712-2011).

Véliz con TP Chile S.A. (2012): Corte Suprema, 12 de octubre de 2012 (recurso de unificación de jurisprudencia rol 820-2012).

Castillo con Jara (2012): Corte Suprema, 23 de octubre de 2012 (recurso de unificación de jurisprudencia rol 1170-2012).

Moya con Ilustre Municipalidad de Frutillar (2012): Corte Suprema, 7 de noviembre de 2012 (recurso de unificación de jurisprudencia rol 12251-2011).

Olivares con Pontificia Universidad Católica de Chile (2012): Corte Suprema, 28 de noviembre de 2012 (recurso de unificación de jurisprudencia rol 1855-2012).

Riquelme con Pontificia Universidad Católica de Chile Corporación de Televisión (2012): Corte Suprema, 28 de noviembre de 2012 (recurso de unificación de jurisprudencia rol 1681-2012).

Pereira con Ilustre Municipalidad de San Esteban (2012): Corte Suprema, 21 de diciembre de 2012 (recurso de unificación de jurisprudencia rol 2658-2012).

Castillo con Bahamonde y Cia Ltda. (2012): Corte Suprema. 28 de diciembre de 2012 (recurso de unificación de jurisprudencia rol 2500-2012). 
Poblete y Otros con Corporación de Desarrollo de la comuna de San Vicente de Tagua Tagua (2012): Corte Suprema, 28 de diciembre de 2012 (recurso de unificación de jurisprudencia rol 2506-2012).

AÑo 2013

Contreras con Ilustre Municipalidad de Puerto Montt (2013): Corte Suprema, 11 de abril de 2013 (recurso de unificación de jurisprudencia rol 2154-2012). 
